Rio de Janeiro. Ano 15. Volume 22. Número 3. Setembro a Dezembro de 2021

Periódico Quadrimestral da Pós-Graduação Stricto Sensu em Direito Processual da UERJ

Patrono: José Carlos Barbosa Moreira (in mem.). ISSN 1982-7636. pp. 781-798

www.redp.uerj.br

\title{
LOS PROCESOS JUDICIALES Y SU IMPERIOSA NECESIDAD DE REFORMA ${ }^{1}{ }^{2}$
}

JUDICIAL CLAIMS AND THEIR URGENT NEED FOR REFORM

María Victoria Mosmann Abogada, Escribana, Especialista en Derecho Procesal Civil, Miembro del Comité Ejecutivo de la Asociación Argentina de Derecho Procesal. Doctoranda por la Universidad de Salamanca. Directora del Instituto de Investigaciones del Colegio de Magistrados de Salta; Fundadora y Miembro honorario de la Comisión de Investigación en Derecho Procesal del Colegio de Abogados de Salta. Directora del Ateneo de Derecho Procesal de Salta (FAEP). Cuenta con publicaciones y participaciones en obras colectivas en Argentina, México, Uruguay, Chile, Brasil, Portugal y Colombia. Jueza de Primera Instancia de la Provincia de Salta. Buenos Aires, Argentina. E-mail: : mvmosmann@gmail.com

María Pía Molina Abogada por la Universidad Católica de Salta. Profesora en Ciencias Jurídicas por la Universidad Nacional de Salta. Magister en Razonamiento Probatorio por la Universidad de Girona, España y por la Universidad Degli Studi di Genova, Italia. Delegada de la provincia de Salta de la Comisión de

\footnotetext{
${ }^{1}$ Artigo recebido em 03/06/2021, sob dispensa de revisão.

${ }^{2}$ Publicado en Revista de Ciencia de la Legislación - Número 9 - Mayo 2021, Editorial IJ Argentina, https://ar.ijeditores.com/pop.php?option=publicacion\&idpublicacion=200\&idedicion $=4820$
} 
Jóvenes Procesalistas de la Asociación Argentina de Derecho Procesal. Buenos Aires, Argentina.

"El grado de eficacia de una democracia constitucional se identifica con el grado de eficacia de las garantías de los derechos constitucionales que se reconocen en ella"

(Ferrajoli)

RESUMO: En el presente artículo las autoras abordan la situación actual en la que se encuentra la justicia civil, destacando las barreras que existen para acceder a ella y la marginalidad subjetiva en la que se encuentra un vasto sector de la población. Con base en ello, se analiza la imperiosa necesidad de reforma al proceso civil con el objeto de sanear la actual crisis de racionalidad y tender a la eficiencia, utilidad y efectividad de los procesos.

PALABRAS CLAVE: Reforma procesal civil, tutela judicial efectiva, igualdad, principio de colaboración, gestión del caso.

SUMMARY: In this paper the authors address the current situation in which civil justice is found, highlighting the barriers that exist to access it and the subjective marginality in which a vast sector of the population finds itself. Based on this, the imperative need to reform the civil process is analyzed in order to correct the current crisis of rationality and tend to the efficiency, usefulness and effectiveness of the processes.

KEYWORDS: Civil procedural reform, effective judicial protection, equality, principle of collaboration, case management.

\section{La situación actual}

Muchos conflictos que emergen de la realidad cotidiana se encuentran con un acceso a la justicia debilitado por la falta de adecuación de los procesos a las especiales 
Rio de Janeiro. Ano 15. Volume 22. Número 3. Setembro a Dezembro de 2021

Periódico Quadrimestral da Pós-Graduação Stricto Sensu em Direito Processual da UERJ

Patrono: José Carlos Barbosa Moreira (in mem.). ISSN 1982-7636. pp. 781-798

www.redp.uerj.br

circunstancias de vulnerabilidad de los sujetos involucrados en él o, en el peor de los casos, lisa y llanamente quedan puertas afuera del sistema judicial.

La justicia civil aparece como un ámbito para algunos, más no para todos. La edad, género, estado físico o mental, las circunstancias sociales, económicas, étnicas o culturales, son algunas de las causas de esta situación de marginalidad judicial. No hablamos aquí de la preocupación respecto a las distinciones entre la justicia "vip" o de "peces gordos" y la que enfrenta el hombre común, sino que la mirada se sienta en la forma inacabada en que la justicia civil alcanza a la generalidad de la población y en particular a los vulnerables.

En este sentido, un relevamiento realizado a nivel mundial por "The World Justice Project" titulado "Measuring the justice gap: A People-Centered Assessment of Unmet Justice Needs Around the World”, arrojó en el año 2019 que 1.5 billones de personas no logran acceder a la justicia civil, administrativa o penal para la resolución de sus conflictos cotidianos; 4.5 billones de personas están excluidas de las oportunidades que el derecho otorga -carecen de herramientas legales, tales como documentos de identidad, contratos de alquiler y acuerdos formales de trabajo-; y 253 millones de personas viven en condiciones de extrema injusticia -apátridas, víctimas de modernas forma de esclavitud, y aquéllas que viven en estados débiles con elevadísimos niveles de inseguridad- ${ }^{3}$.

Por su parte, en el ámbito local como parte del Programa "Justicia 2020”, durante los meses de mayo a noviembre de 2019 se elaboró un "Relevamiento Nacional de Necesidades Jurídicas insatisfechas", el cual arrojó como resultado que dos tercios de la población ha experimentado problemas jurídicos en los últimos tres años y que el 16,3\% presenta necesidades jurídicas insatisfechas; entendiendo como tales a aquellas necesidades jurídicas frente a las cuales el sujeto no ha actuado, o bien cuando habiendo actuado, se encuentra insatisfecho respecto de las respuestas obtenidas como resultado de su propio accionar o el de terceros. Se presentan, así, como una brecha entre la experimentación de una necesidad jurídica y la resolución satisfactoria de la misma ${ }^{4}$.

\footnotetext{
${ }^{3}$ World Justice Program (2019) Measuring the justice gap: A People-Centered Assessment of Unmet Justice Needs Around the World. https://worldjusticeproject.org/our-work/publications/special-reports/measuringjustice-gap

${ }_{4} \quad$ https://www.argentina.gob.ar/justicia/afianzar/caj/justicia/afianzar/caj/politica-de-gobiernoabierto/diagnostico-de-necesidades-juridicas-insatisfechas-y-niveles
} 
Rio de Janeiro. Ano 15. Volume 22. Número 3. Setembro a Dezembro de 2021

Periódico Quadrimestral da Pós-Graduação Stricto Sensu em Direito Processual da UERJ

Patrono: José Carlos Barbosa Moreira (in mem.). ISSN 1982-7636. pp. 781-798

www.redp.uerj.br

Estos datos evidencian clara y crudamente que no todos aquellos individuos ni grupos de personas que requieren de la función jurisdiccional para el ejercicio o defensa de sus derechos, logran efectivamente acceder a la justicia. En efecto, existen distintas y variadas barreras que impiden a un gran sector de la población el goce de un derecho fundamental, cual es la tutela judicial efectiva; lo que no sólo patentiza sino que, además, profundiza aún más las desigualdades sociales, económicas o culturales. Es que, como lo ha sostenido la Comisión Interamericana de Derechos Humanos, el Poder Judicial constituye la primera línea de defensa a nivel nacional para la protección de los derechos y las libertades individuales, y por ello la importancia de su respuesta efectiva ${ }^{5}$.

Lo expuesto demuestra que pese a los avances en el reconocimiento de los derechos que surgen no sólo de la reforma constitucional de 1994 y los tratados incorporados en ella, sino también del texto del código civil y comercial, resta aún mucho por hacer a los efectos de que tales derechos puedan ser efectivamente tutelados.

Muchos son los que quedan en la banquina del proceso, quienes no lo comprenden, o no pueden asumir sus costos, quienes entienden que el proceso no habrá de darles respuesta -configurando una marginalidad subjetiva-, o que ella les llegará demasiado tarde, ellos aparecen dejados al margen de su alcance. Esta segregación que deja fuera de las fronteras del proceso a quienes son incapaces de arribar al umbral de acceso a la justicia necesita ser paleada y equilibrada con medidas afirmativas, que sumen a quien lo necesita el suficiente contenido positivo para poder llegar al final buscado en el proceso, con tantas posibilidades de éxito y efectividad como cualquier otro ciudadano.

El camino de los cambios sociales que la constitución reformada delineó a partir del reconocimiento de derechos de las minorías y sectores vulnerables, se ha visto dilatado por la inefectividad de los derechos. Podemos decir que contamos con el reconocimiento formal de derechos, pero que su efectividad, en un importante número de casos, se encuentra afectada, y que la reforma de los procesos aparece necesaria para la lograr la

Otro dato interesante que surge del relevamiento citado es que el $16.2 \%$ de quienes experimentan un conflicto legal no toma ninguna medida activa para enfrentarlo y que el $29.1 \%$ intento resolverlo por su propia cuenta.

${ }^{5}$ Informe OEA/SER.L/V/II.Doc. 6820 enero 2007, “Acceso a la justicia para las mujeres víctima de violencia en las Américas". 
Rio de Janeiro. Ano 15. Volume 22. Número 3. Setembro a Dezembro de 2021

Periódico Quadrimestral da Pós-Graduação Stricto Sensu em Direito Processual da UERJ

Patrono: José Carlos Barbosa Moreira (in mem.). ISSN 1982-7636. pp. 781-798

www.redp.uerj.br

transformación social, que según Chase $^{6}$, se produciría como efecto de ese círculo virtuoso entre proceso y cultura.

Ese estado de situación generó que, en los hechos, muchos de los reclamos jurisdiccionales realizados invocando los nuevos derechos no contaran con vías aptas para lograr su restablecimiento, y en consecuencia se mostrara al sistema judicial como ineficaz, el proceso aparece negando o limitando los derechos que la constitución reconoce.

\section{La necesaria reforma procesal}

Lo desarrollado en el apartado que antecede patentiza no sólo la existencia de múltiples barreras que impiden a un vasto grupo de sujetos acceder a la justicia, sino que evidencia también la crisis de racionalidad la ley procesal, de la que hablaba el profesor Michele TARUFFO ya en el año 1999. Es que, como enseña el citado autor, la ley procesal es racional en sentido instrumental si regula un procedimiento que sirve adecuadamente a los fines de la administración de la justicia ${ }^{7}, y$, como quedó expuesto anteriormente, la realidad nos demuestra claramente que los actuales procesos no se presentan como herramientas eficientes para la consecución de tales fines.

La reforma constitucional de 1994 logró respecto al reconocimiento de derechos un avance que puede dimensionarse como de alto impacto jurídico, pero no logramos aún que el sistema judicial brinde una respuesta adecuada a quienes necesitan solución a sus conflictos fundado en derechos de orden constitucional, y que por diversos motivos no conforman la media para la cual fue pensada la ingeniería del proceso civil. Los procesos, en gran medida, no se adecuan a la Constitución ni a los tratados incorporados a ella en el art. 75 inc. 22, y llevan décadas de deuda de adaptación legislativa.

Ello ha llevado a plantearse, no sólo en el ámbito local sino en toda Latinoamérica, la necesidad de reformas procesales que se hagan cargo de las insuficiencias o falencias de los actuales sistemas procesales. No hay dudas de que el proceso civil debe ser reformado,

\footnotetext{
6 Autor citado, Derecho, cultura y ritual: sistemas de resolución de controversias en un contexto intercultural, Marcial Pons, Ediciones Jurídicas y Sociales, 2011, Madrid. España

7 TARUFFO, Michele, 'Racionalidad y Crisis de La Ley Procesal', Doxa, 22, 1999, 311-20.
} 
Rio de Janeiro. Ano 15. Volume 22. Número 3. Setembro a Dezembro de 2021

Periódico Quadrimestral da Pós-Graduação Stricto Sensu em Direito Processual da UERJ

Patrono: José Carlos Barbosa Moreira (in mem.). ISSN 1982-7636. pp. 781-798

www.redp.uerj.br

a los efectos de garantizar efectivamente la tutela judicial efectiva. Sin embargo, se advierte que ello no requiere sólo de un cambio legislativo, sino también y fundamentalmente, de un cambio cultural.

Ahora bien, pensar en reformas procesales obliga, en primer término, a discutir sobre el objeto o la finalidad hacia el cual debe tender el proceso y la función jurisdiccional, pues como señala ALAN UzELAC tal discusión se constituye en una precondición para alcanzar reformas procesales exitosas, especialmente si se aspira a que dichas reformas sean profundas, trascendentales y efectivas ${ }^{8}$.

$\mathrm{Al}$ respecto, en el derecho comparado se observa que los dos principales objetivos en base a los cuales se estructuran los procesos civiles, son los siguientes: resolución de los conflictos individuales por los órganos judiciales e implementación de políticas y funciones públicas y sociales.

Consideramos que el diseño procesal debe tender a equilibrar y cohonestar ambas propósitos, pues partimos de la convicción de que los conflictos que se presentan ante el sistema de administración de justicia deben ser resueltos a través de una decisión que se funde "en la correcta aplicación de la ley a las circunstancias del caso concreto", por lo que entendemos que el proceso no puede ser confiado exclusivamente a la libre voluntad de las partes. Es que, junto a los intereses particulares de los litigantes, convergen los del Estado y los de toda la sociedad democrática en la recta administración de la justicia.

Ello evidencia que el proceso no puede ser confiado exclusivamente a los intereses particulares, sino que, por el contrario, resulta necesario que el juez asuma un rol más activo en su dirección y que cuente con las herramientas necesarias a los efectos de maximizar las posibilidades de obtener decisiones de calidad y conforme a derecho.

El Proyecto de Código Procesal Civil y Comercial de la Nación ${ }^{10}$, redactado en el marco del Programa Justicia 2020, asume explícitamente estos fines, ya que parte del reconocimiento de que el primero de los derechos que deben ser garantizados a los

\footnotetext{
${ }^{8}$ UZELAC, Alan (Ed.), Goals of Civil Justice and Civil Procedure in Contemporary Judicial Systems, Ius Gentium:Comparative Perspectives on Law and Justice, 2014, pp. 5 y 6.

${ }^{9}$ TARUFFO, Michele, Simplemente La Verdad. El Juez y La Construcción de Los Hechos, Madrid: Marcial Pons, 2010, p. 133.

${ }^{10}$ Puede consultarse en https://www.justicia2020.gob.ar/noticias/fundamentos-del-proyecto-codigo-procesalcivil-comercial-la-nacion El proyecto fue presentado en septiembre de 2019, MEN-2019-178-APN-PTE
} 
Rio de Janeiro. Ano 15. Volume 22. Número 3. Setembro a Dezembro de 2021

Periódico Quadrimestral da Pós-Graduação Stricto Sensu em Direito Processual da UERJ

Patrono: José Carlos Barbosa Moreira (in mem.). ISSN 1982-7636. pp. 781-798

www.redp.uerj.br

justiciables es el derecho a un proceso eficiente, útil y efectivo (art. 13), estableciendo, a la vez, que las normas procesales deben ser interpretadas, observando los fines sociales del proceso y las exigencias del bien común (art. 1), reconociendo así a la tutela judicial efectiva como principio y como derecho ${ }^{11}$.

En el mismo sentido, ya en el documento denominado "Bases para la reforma procesal civil" 12 redactado por la misma comisión que luego escribió el citado proyecto, se planteó como objetivo de la reforma la elaboración, implementación y evaluación de políticas para construir una justicia que genere resultados socialmente relevantes y permita la solución de los conflictos en forma rápida y confiable.

De estos dos instrumentos se desprende claramente la función instrumental que el proceso está destinado a cumplir, en tanto herramienta para garantizar o reestablecer el ejercicio y goce de los derechos sustanciales reconocidos por el ordenamiento jurídico.

Ello obliga a repensar la justicia como un servicio público que debe ser eficaz y tender a la satisfacción de los derechos de quienes acuden a ella, poniendo el eje de protección en los derechos y las personas.

\section{Pensar la reforma procesal civil}

El derecho de acción hoy no es simplemente el derecho de pedir la resolución del litigio, sino que el derecho de acción tiene diversos corolarios, comenzando con el derecho a participar adecuadamente del proceso, mediante la presentación de alegaciones y la producción de pruebas en un plazo razonable, y de influir sobre el convencimiento del juez ${ }^{13}$, contenidos estos que integran el contenido mínimo de la tutela judicial efectiva o, su núcleo duro ${ }^{14}$. La concepción del derecho irrestricto de acceso a la justicia quedó subsumida en el más amplio y abarcador derecho fundamental a la tutela

${ }^{11}$ OTEIZA - MOSMANN, Tutela Judicial Efectiva: principio y derecho, en proceso de publicación editorial Rubinzal Culzoni.

${ }^{12}$ Las Bases pueden ser consultadas en http://www.saij.gob.ar/bases-para-reforma-procesal-civil-comercialministerio-justicia-derechos-humanos-nacion-lb000214-2017-08/123456789-0abc-defg-g41-2000blsorbil

${ }^{13}$ MARINONI, L. G., El derecho fundamental de acción, Boletín Mexicano de Derecho Comparado, Nueva Serie, Año XLI, número 123, septiembre diciembre de 2008, pág. 1385.

${ }^{14}$ BERIZONCE R., Los contratos y el negocio jurídico procesal, RDP, Rubinzal-Culzoni ed., Bs.As. 2017-2, p78. 
Rio de Janeiro. Ano 15. Volume 22. Número 3. Setembro a Dezembro de 2021

Periódico Quadrimestral da Pós-Graduação Stricto Sensu em Direito Processual da UERJ

Patrono: José Carlos Barbosa Moreira (in mem.). ISSN 1982-7636. pp. 781-798

www.redp.uerj.br

judicial eficiente y efectiva, la "garantía de las garantías", el derecho a hacer valer todos los demás derechos ${ }^{15}$.

La tutela judicial fue adquiriendo contenidos, que la calificaron así como la garantía de la tutela judicial "efectiva", abandonando la rígida concepción formalista de la mera recepción legal para pasar a preocuparse por la vigencia efectiva de los derechos, y por la persona real y concreta frente a su situación de acceso a la justicia garantizándole la efectividad de los derechos sustanciales reclamados y la igualdad de posibilidades de defensa conforme a sus especiales circunstancias ${ }^{16}$.

Tal como lo ha marcado en su texto el Proyecto de Reforma del Código Procesal Civil y Comercial, al prever el principio a la tutela judicial efectiva en su artículo primero diciendo que "las normas procesales se interpretarán con el objeto de lograr la efectividad de los derechos sustanciales, observando los fines sociales del proceso, las exigencias del bien común, la eficiencia, la legalidad, la proporcionalidad y la razonabilidad, procurando afianzar la tutela judicial efectiva, en especial para los casos de personas en situación de vulnerabilidad. Se asegurará a las partes la igualdad real de oportunidades para la defensa de sus derechos, removiendo los obstáculos que impidan o dificulten su ejercicio o coloquen a una de ellas en condición de inferioridad jurídica”. En este contexto de búsqueda de efectividad del derecho procesal, y de democratizarlo llegando a la mayor cantidad de personas posible ${ }^{17}$ es que pensamos la reforma del proceso civil y comercial, dándole al proceso civil la perspectiva de recipiendario de las garantías constitucionales, las que descienden así al rango legal con forma de principios de interpretación, e integración normativa evolucionando de modo positivo y concreto hacia la efectividad de los derechos, en relación a las pretensiones que traen al proceso y a sus especiales circunstancias las que deben ser consideradas para garantizar la igualdad, y dar

\footnotetext{
${ }^{15}$ BERIZONCE, R., Revista Derecho y Ciencias Sociales, Abril 2012. No6 (Acceso a la Justicia). Pgs.25-37. ISNN 1852-2971 Instituto de Cultura Jurídica y Maestría en Sociología Jurídica, FCJ y S. UNLP

${ }^{16}$ MOSMANN, Tutela judicial efectiva, Revista Ius Dictum, Associação Académica da Faculdade de Direito da Universidade de Lisboa, 2020, Phttps://biblioteca.cejamericas.org/handle/2015/5640 ortugal.

${ }^{17}$ Sobre la deuda de democratizar el proceso civil, ver los desarrollos realizados en OTEIZA- MOSMANN, Tutela Judicial Efectiva: principio y derecho, obra colectiva en prensa.
} 
Revista Eletrônica de Direito Processual - REDP.

Rio de Janeiro. Ano 15. Volume 22. Número 3. Setembro a Dezembro de 2021

Periódico Quadrimestral da Pós-Graduação Stricto Sensu em Direito Processual da UERJ

Patrono: José Carlos Barbosa Moreira (in mem.). ISSN 1982-7636. pp. 781-798

www.redp.uerj.br

cumplimiento al carácter instrumental del proceso, tanto en su faz objetiva, como subjetiva $^{18}$.

La tutela judicial efectiva, la proporcionalidad de los procesos, la oralidad y a inmediación entre el juez y las partes, la dirección del proceso por parte de los magistrados, la colaboración como forma de trabajo de los actores del proceso, son ejes sobre los que existe un alto grado de coincidencia y que repasaremos a fin de dar un recorrido por el camino que estimamos debe transitar la reforma ${ }^{19}$.

Esta coincidencia a la que nos referimos se ha visto receptada por en el texto del Proyecto del Código Procesal Civil y Comercial, en tanto en su Título Preliminar, en los artículos del 1 al 12, regula los principios que habrán de regir el proceso enumerando como se dijo- en primer lugar el principio de tutela judicial efectiva y luego el de inmediación, concentración y oralidad ${ }^{20}$, dirección del proceso, iniciativa en el proceso aportación y derecho de contradicción, impulso procesal oficioso, lealtad, buena fe y deber de decir verdad, economía, celeridad y concentración procesal, transparencia y publicidad,

\footnotetext{
${ }^{18}$ MOSMANN, María Victoria, Instrumentalidad subjetiva del proceso, Revista de la Asociación Argentina de Derecho Procesal, Año VIII, N ${ }^{\circ}$ 10, agosto de 2014, pág. 197; Processo e sujeitosvulneraveis. Instrumentalidade procesual de equiparacao subjetiva, Revista Iberoamericana de Derecho Procesal RIDP, Año 1.2. 2015, pág. 119; Ejecución de Sentencia y Plazo Razonable. Ejecución Anticipada de Sentencia. Revista de Derecho Procesal 2013/2 RubinzalCulzoni; Requerimientos que llegan a la justicia civil. Los procesos judiciales a casi 20 años de la última reforma constitucional. Revista Voces en el Fénix Año 4 №30, noviembre de 2013. Ediciones Especiales de Pagina 12 a cargo del Plan Fénix y coordinada por la Dra. Ángela Ledesma; Estudios de Derecho Procesal en homenaje a Eduardo J. Couture publicada en 2017 en Uruguay por Editorial La Ley Uruguay, el Instituto Iberoamericano de Derecho Procesal y la Asociación Uruguaya de Derecho Procesal "Eduardo J. Couture".(Tomo I)I.S.B.N. 978-9974-731-73-8 (Obra completa); Instrumentalidad Subjetiva del Proceso. Argentina y el Contexto de América Latina. Libro publicado en Brasil Motivacao no CPC/2015 e MaisAlem ISBN 978-85-519-0424-4; El Proceso de Familia. Adaptaciones pendientes desde la Reforma de la Constitución Nacional de 1994, en la obra colectiva Derecho Procesal Constitucional. Fragmentos y testimonios a 25 años de la reforma de la Carta Magna, IJ Editores, 2019, IJCMIX-983

${ }^{19}$ Se pueden consultar las opiniones doctrinales que se encuentran en obras colectivas como Reforma Procesal Civil, coordinada por Eduardo Oteiza, Rubinzal Culzoni, 2010; Análisis de las Bases para la Reforma Procesal Civil y Comercial, coordinada por Jorge A. Rojas, Rubinzal Culzoni 2018; Sendas de la reforma de la justicia a principios del siglo XXI, coordinada por Eduardo Oteiza, Marcial Pons, España, 2018; Los Principios Procesales, RDP 2020-1, Rubinzal Culzoni; entre muchos otros.

${ }^{20}$ Proyecto del Código Procesal Civil y Comercial, articulo 2: se garantizará la inmediación del juez con las partes, los sujetos intervinientes y el material de conocimiento. A esos fines se concentrará la actividad procesal, la que se desarrollará en forma preferentemente oral y en audiencias. Los jueces presenciarán las declaraciones de las partes y de los testigos, los careos, las exposiciones, explicaciones y respuestas que hayan de ofrecer los peritos, así como la crítica oral de su dictamen y cualquier otro acto de prueba que, conforme a lo dispuesto en este Código, deba llevarse a cabo contradictoria y públicamente
} 
Rio de Janeiro. Ano 15. Volume 22. Número 3. Setembro a Dezembro de 2021

Periódico Quadrimestral da Pós-Graduação Stricto Sensu em Direito Processual da UERJ

Patrono: José Carlos Barbosa Moreira (in mem.). ISSN 1982-7636. pp. 781-798

www.redp.uerj.br

adaptabilidad de las formas procesales, colaboración, preclusión y no exigibilidad de otra conducta.

En este marco, y partiendo de la idea de que los procesos deben ser eficientes, útiles y efectivos y concluir en un plazo razonable, aparece como imperiosa la necesidad de dotar a los jueces de la causa de facultades de dirección y gestión del proceso, al efecto de que puedan administrar efectiva y eficientemente los escasos recursos con los que la administración de justicia cuenta.

De este modo, se busca quebrar con la lógica actual en virtud de la cual se confía el impulso y desarrollo del proceso exclusivamente a los intereses y estrategias de las partes, pues se entiende que la justicia, en tanto constituye un servicio público, debe ser eficientemente administrada.

La gestión de casos se presenta, entonces, como "un enfoque para el control del litigio en el que el tribunal asume una mayor responsabilidad por el progreso de los casos hasta las etapas previas al juicio para garantizar que los recursos del tribunal se desplieguen adecuadamente y se reduzcan las demoras y retrasos judiciales"21.

En tal sentido, adquiere relevancia la idea de proporcionalidad ${ }^{22}$, conforme a la cual el proceso adoptado para resolver una disputa determinada debe ser -considerando costos y duración- proporcional al valor, importancia y complejidad del asunto llevado a conocimiento del Tribunal. La proporcionalidad refiere, entonces, a "la necesidad de establecer un equilibrio entre lograr un resultado justo y el tiempo y los costos invertidos para lograr ese resultado" ${ }^{23}$. Los elevados costos del proceso actual impactan tanto en el Estado, como en el litigante, para el que muchas veces resulta obstativo e impeditivo de sus posibilidades de acceso al sistema de justicia.

A su vez, junto al "manejo del caso" por parte del juez, la reforma debe incorporar el principio de colaboración. Tanto las partes como el tribunal deben cooperar para

\footnotetext{
${ }^{21}$ FANDIÑO, Marcos (dir.), Estudios Comparados sobre reformas al Sistema de Justicia Civil Australia y Canadá, Volumen II, CEJA, publicado en https://biblioteca.cejamericas.org/handle/2015/5640

${ }^{22}$ SUCUNZA afirma que "Repensar la legalidad significa transformar la concepción y modo en que las fuentes normativas y los sujetos se vinculan para definir el mecanismo y manera más adecuada para procesar un conflicto. De allí que consideremos que la contradicción expuesta deba resolverse en favor de un esquema que conciba a la legalidad como un concepto vivo, dinámico y maleable (proceso flexible). Un esquema que sintetice las posiciones encontradas aportando racionalidad entre estructuras, medios y fines".

${ }^{23}$ Ibídem, p. 117.
} 
Rio de Janeiro. Ano 15. Volume 22. Número 3. Setembro a Dezembro de 2021

Periódico Quadrimestral da Pós-Graduação Stricto Sensu em Direito Processual da UERJ

Patrono: José Carlos Barbosa Moreira (in mem.). ISSN 1982-7636. pp. 781-798

www.redp.uerj.br

promover la resolución justa, eficiente y rápida de la disputa. Lo que debe procurarse es establecer "una verdadera comunidad de trabajo" entre todos los participantes del proceso y favorecer un constante intercambio dialógico entre ellos con el objeto de arribar a una decisión de mérito justa y efectiva ${ }^{24}$.

Como sostiene SucunZA, la cooperación deberá introducirse como principio. Es decir, como directriz que sirva para explicitar, promover e interpretar el estado de cosas diseñado y resolver las tensiones existentes de manera funcional al sentido que las inspira, no ciñéndola a la cooperación como conducta (de las partes, terceros o juez), ni dilema meramente ético, sino que propone asumirla además como un concepto holístico, transversal y utilitario al ejercicio de derechos y estructura de poder ${ }^{25}$.

Sin dudas, concebir y estructurar el proceso desde una óptica cooperativa requiere de un cambio cultural, pues implica una nueva forma de resolver y enfrentar, en el marco jurisdiccional, los conflictos intersubjetivos. Se sustenta en la activa participación de todos los sujetos comprometidos y no exclusivamente en la función de adjudicación del juez. Es entonces necesario diseñar un proceso que propicie e incentive el intercambio dialógico, a la vez que efectivamente desmotive la adopción de conductas dilatorias o entorpecedoras del proceso.

A tales fines y a modo de ejemplo, debieran introducirse concretos deberes $-\mathrm{y}$ no simples cargas- de aportación de prueba ${ }^{26}$ o fomentar los acuerdos procesales entre las partes. Incluso, tal como se sostiene en las "Bases para la reforma procesal Civil y Comercial", la aplicación de este principio implica modificar criterios jurídicos o prácticas que se han revelado inconvenientes, tal como la de autorizar al demandado a limitarse a negar los hechos invocados por la actora sin aportar su versión fáctica, pese a haber

\footnotetext{
${ }^{24}$ MITIDIERO, DANIEL, “Colaboracao no proceso civil”, 3era. Edición. Revista dos Tribunais., 2015, ps. 64, 65 y 99.

${ }^{25}$ SUCUNZA, Matías, Cooperación como modelo (y principio) procesal: cambio de paradigma e interpelaciones en pro de una reforma igualitaria, responsable y democrática, publicado en https://www.aadproc.org.ar/pdfs/Jornadas/2018/SUCUNZA\%20\%20Cooperacion\%20como\%20modelo....pd $\mathrm{f}$

${ }^{26}$ Al respecto ver De Paula Ramos, Vitor, Ônus Da Prova No Processo Civil. Do Ônus Ao Deber de Provar, 2da. ed. San Pablo: Thomson Reuters Brasil, 2018.
} 
Rio de Janeiro. Ano 15. Volume 22. Número 3. Setembro a Dezembro de 2021

Periódico Quadrimestral da Pós-Graduação Stricto Sensu em Direito Processual da UERJ

Patrono: José Carlos Barbosa Moreira (in mem.). ISSN 1982-7636. pp. 781-798

www.redp.uerj.br

participado del episodio llevado a juicio ${ }^{27}$, pues ello resulta contrario a la lealtad, buena fe y veracidad con el que las partes deben actuar en el marco de un proceso judicial.

A su vez, un modelo colaborativo exige imponer sanciones efectivas en caso de incumplimiento de los deberes, las cuales pueden consistir en la posibilidad de extraer inferencias negativas a partir de la conducta renuente de alguna las partes; la imposición de costas, astreintes o multas al incumplidor; o incluso, en caso de comprobarse una falta grave, la sanción puede consistir en considerar en rebeldía a quien se resiste a acatar las reglas. El Proyecto del Código Procesal Civil y Comercial de la Nación en sus artículos 6, $10,15,16,45,311,439$, entre otros, se muestra acorde con este sentido.

A más de ello, consideramos que los diseños procesales debieran promover la inmediación del juez con las partes y con la prueba ${ }^{28}$. Entendemos que el proceso por audiencias, con la consecuente inmediación que conlleva, resulta beneficioso en tanto permite, por un lado, la efectiva vigencia del principio de contradicción entre las partes y, por el otro, la participación directa del juez en la práctica de la prueba, lo que a su vez, garantiza la obtención de información de calidad para la toma de decisión por parte del juzgador. Es que, la oralidad es un método que permite, a través de su dinámica dialógica, obtener mejor información para verificar la calidad de las hipótesis fácticas alegadas por las partes. En este sentido, Ferrer Beltrán señala que "es en el marco del juicio oral donde el juez deberá tener una percepción directa de la práctica de las pruebas que le pondrá en la mejor posición epistemológica para valorarlas"29.

En efecto, la inmediación permite tanto al juez como a las partes controlar la producción de los distintos medios de prueba y así obtener mayores elementos para valorar su fiabilidad, lo cual claramente redundará en la calidad de la decisión ya que, como sostiene TARUFFO, la decisión será "buena si pone fin al conflicto estando justificada en

\footnotetext{
27 "Bases para la reforma procesal Civil y Comercial”, p. 22

${ }^{28}$ Tal como surge del ya citado artículo 2 del Proyecto de Código Procesal Civil y Comercial.

${ }^{29}$ FERRER BELTRÁN, Jordi, 'El Control de La Valoración de La Prueba En Segunda Instancia', Revus, 33, 2017, p. 2.
} 
Rio de Janeiro. Ano 15. Volume 22. Número 3. Setembro a Dezembro de 2021

Periódico Quadrimestral da Pós-Graduação Stricto Sensu em Direito Processual da UERJ

Patrono: José Carlos Barbosa Moreira (in mem.). ISSN 1982-7636. pp. 781-798

www.redp.uerj.br

criterios jurídicos y racionales, entre los que asume una importancia particular la verdad de la determinación de los hechos" ${ }^{30}$.

No obstante ello, no puede soslayarse que pese a que la inmediación, como se dijo, es beneficiosa en tanto permite al juez percibir los resultados de los distintos elementos de prueba sin intermediarios -y, así, depurar la información que ingresa al proceso-, conlleva el riesgo de que se acudan a criterios subjetivos de valoración, sobre todo en los casos de la prueba testimonial o de declaración de parte. En este sentido, es frecuente observar, por ejemplo, que los jueces al apreciar la credibilidad de los testigos acudan a simples impresiones o intuiciones respecto a la persona del declarante, para lo cual se valora su conducta en el momento de prestar su declaración (si titubea, si se muestra nervioso, hacia donde mira, etc.). Sin embargo, los especialistas en psicología del testimonio sostienen que no existen indicadores conductuales que revelen si una persona está mintiendo, razón por la cual a los fines de valorar la fiabilidad de la prueba testimonial debe analizarse la declaración -y no al declarante- con base en criterios objetivos y explicables ${ }^{31}$.

Es que la valoración de la información obtenida no se reduce a la simple percepción de lo acontecido en la audiencia: el juez debe, además, valorar la calidad epistemológica de los distintos elementos de prueba, es decir, debe analizar su credibilidad y fuerza probatoria, lo que sólo podrá establecerse a través de inferencias. Por tales motivos, es que consideramos de vital importancia la formación en materia epistemológica de los distintos operadores.

La inmediación que conlleva la realización de audiencias implica a su vez que las desigualdades que pudiesen existir entre las partes queden a la vista, justo delante del magistrado, sin que sean intermediadas por el lenguaje técnico del abogado como sucede en el sistema escrito, el que iguala y disimula las situaciones de desventaja de las personas. Así la vulnerabilidad en la que pudiese estar inmersa una de las partes podrá ser advertida $\mathrm{y}$ atendida por el magistrado a fin de garantizar la igualdad real de los contendientes,

\footnotetext{
30 TARUFFO, Michele, "Poderes probatorios de las partes y del juez en Europa. Doxa. Cuadernos de Filosofía del Derecho", LX(29), 249-271. https://doi.org/10.14198/doxa2006.29.13, p. 266.

31 Al respecto ver, por ejemplo MANZANERo, Antonio Psicología Del Testimonio (Madrid: Ediciones Pirámide, 2008).
} 
Revista Eletrônica de Direito Processual - REDP.

Rio de Janeiro. Ano 15. Volume 22. Número 3. Setembro a Dezembro de 2021

Periódico Quadrimestral da Pós-Graduação Stricto Sensu em Direito Processual da UERJ

Patrono: José Carlos Barbosa Moreira (in mem.). ISSN 1982-7636. pp. 781-798

www.redp.uerj.br

haciendo uso de medidas positivas de igualación, adaptando las formas a las especiales necesidades de quien se encuentre involucrado en el litigio.

Por otro lado, resulta evidente que las futuras reformas deben incorporar herramientas y sistemas tecnológicos a los procesos, a los fines de dotarlos de mayor eficiencia, celeridad y transparencia.

Claramente, la actual situación epidemiológica y sus consecuencias nos han demostrado lo rudimentarios y desactualizados que resultan nuestros sistemas y los inconvenientes que ello genera. ¿Cuantos procesos se han visto paralizados porque la infraestructura de las tecnologías que dan soporte al servicio de administración de justicia no estuvo a la altura de las circunstancias? ¿Qué enseñanzas nos ha dejado la pandemia en torno a la forma de funcionamiento de las oficinas judiciales $?^{32}$.

Sin dudas, esta situación debe servirnos para darnos cuenta de que "cuando mantenemos procesos de trabajo prescindiendo de los medios a nuestra disposición y de los principios que los inspiraron, esos procesos se distorsionan" 33 y que deben realizarse las inversiones necesarias en materia tecnológica e informática para optimizar la prestación del servicio de justicia, acercando la justicia a las partes, sin desconocer la amplia brecha digital que existe en una sociedad como la nuestra y los impactos que puede tener en el acceso a la justicia de aquellas personas que se encuentran en condiciones desfavorables.

Por último, un aspecto que no ha sido siempre abordado al pensarse en reformas judiciales y que entendemos debe ser repensado y reestructurado es el referente al sistema de precedentes judiciales.

\footnotetext{
${ }^{32}$ Sobre el formato del expediente y las limitaciones generadas por el Aislamiento Social Preventivo Obligatorio derivado de la Pandemia por Covid-19 puede verse MOSMANN, El Rol del Derecho Procesal en la Emergencia: garantías y estabilidad de los actos, Temas de Derecho Procesal, mayo 2020, Erreius "Prestar el servicio de justicia sin poder atender al público implica una serie de adaptaciones modales para las que el sistema de justicia no está alistado en plenitud y tampoco los recursos con los que se cuenta. Los tribunales del país se encuentran encaminados al expediente digital, con mayor o menor grado de aproximación, y con mayores o menores recursos. Ahora bien, estar en "camino a" es demostrativo de que no hemos llegado a la meta, y que la situación de aislamiento obligatorio enfrenta a los argentinos con un Poder Judicial que se maneja con el expediente en soporte papel y sin haber implementado el expediente digital aún".

${ }^{33}$ CHAYER, Héctor M.; MARCET Juan Pablo Marcet (dir), Nueva gestión judicial. Oralidad en los procesos civiles, Ciudad Autónoma de Buenos Aires : Ediciones SAIJ, p.12. Disponible en http://www.saij.gob.ar/docs-f/ediciones/libros/Nueva_gestion_judicial.pdf
} 
Rio de Janeiro. Ano 15. Volume 22. Número 3. Setembro a Dezembro de 2021

Periódico Quadrimestral da Pós-Graduação Stricto Sensu em Direito Processual da UERJ

Patrono: José Carlos Barbosa Moreira (in mem.). ISSN 1982-7636. pp. 781-798

www.redp.uerj.br

Ello por cuanto, al ampliarse las facultades del juez en relación a la interpretación del derecho -tarea para la cual deberá acudir no sólo al texto de la ley, sino también a consideraciones atinentes a la moral, a los valores y a principios- se abre paso también a la subjetividad del juzgador. Por esta razón se ha sostenido que este modelo puede devenir en lo que se ha denominado "decisionismo judicial" y conducir a la inestabilidad e inseguridad en la aplicación e interpretación del derecho.

A los fines de no caer en tal extremo se impone como necesario, por un lado, una adecuada fundamentación racional de las decisiones jurisdiccionales $\mathrm{y}$, por el otro, un replanteamiento del sistema de precedentes, pues resulta claro que "nada puede ser más injusto que tratar casos iguales de forma desigual frente a un mismo ordenamiento jurídico, en un mismo espacio de tiempo 34 ", que "el significado de un derecho fundamental no puede variar en función del juez o tribunal que conozca el caso" ${ }^{35}$, y "la igualdad ante la ley impone una solución a este escenario que permita que el sistema judicial, de modo formal, se vea obligado a dar igual solución ante un caso análogo"36.

A tales efectos, y con el objetivo de dotar de seguridad al ordenamiento jurídico, de fomentar la unidad del derecho y de garantizar la igualdad entre las partes, resulta necesario que los diseños procesales establezcan qué caracteres debe revestir una decisión judicial para constituir un precedente ${ }^{37}$; cuál es la fuerza vinculante-vertical y horizontalde estos últimos; en qué supuestos es legítimo apartarse del precedente, etc.

\section{A modo de conclusión}

Oscar G. Chase, en su trabajo Derecho, cultura y ritual, afirma que, cuando la cultura sufre un cambio sustancial, con independencia del motivo que lo cause, con el tiempo las formas de resolución de controversias harán lo mismo, y también sucederá ello en sentido contrario, y entiende así que su teoría sobre la litigiosidad tiene utilidad

\footnotetext{
${ }^{34}$ MITIDIERO, Daniel, Precedentes, 3era. ed, San Pablo: Thomson Reuters Brasil, 2018.

${ }^{35}$ MARINONI, Guilherme Luiz, La Ética de Los Precedente, Lima: Palestra editores, 2017, p. 47.

${ }^{36}$ MOSMANN, María Victoria, El precedente judicial en Argentina, Revista de Derecho Público 2016-1, Cuestiones Procesales del federalismo argentino, Ed. Rubinzal Culzoni

${ }^{37}$ Ver el análisis realizado en Mosmann, El precedente judicial en Argentina, Revista de Derecho Público 2016-1, Cuestiones Procesales del federalismo argentino, Ed. Rubinzal Culzoni.
} 
predictiva. En ese razonamiento aparece configurada una relación simbiótica entre cultura y proceso, sobre la cual se muestra la incidencia recíproca de ambos.

$\mathrm{Si}$ queremos una sociedad respetuosa de los derechos, debemos contar con procesos efectivos ya que, por el contrario, la anomia devalúa el vínculo de sumisión a la norma restando efectividad. Oteiza afirma que la correspondencia entre un sistema de reglas y los mecanismos para hacerlas efectivas en caso de incumplimiento revela en qué medida esas normas tienen una real aspiración de ser respetadas y que la debilidad de los instrumentos, institucionales y procesales, para lograr esa efectividad tiene un profundo significado cultural.

Cerrando el punto con Ferrajoli, existe una obligación del legislador como correlato de la estipulación de derechos, que consiste en desarrollar una legislación de aplicación de los mismos, y que ella constituye una garantía constitucional positiva indispensable para la efectividad de los derechos fundamentales establecidos por la Constitución. Y es el mismo autor quien observa que en la ineficacia de las garantías legislativas, esto es, de las leyes de desarrollo de los derechos constitucionales establecidos (en especial de los derechos sociales como el derecho a la salud, a la educación y a la subsistencia) es donde reside hoy el principal factor de ilegitimidad constitucional de nuestros ordenamientos.

En el marco de tales lineamientos, resulta claro que una reforma procesal es necesaria a los efectos de que el proceso cumpla efectivamente con su función instrumental, pues la función jurisdiccional adquiere un rol trascendente en la configuración del estado constitucional, toda vez que al sancionar y reparar, e incluso prevenir, las violaciones a los derechos fundamentales de los ciudadanos, permite garantizar la vigencia de los valores democráticos y estimamos que las líneas que aquí desarrollamos contribuyen a este fin, en un proceso civil que lleva décadas de atraso y falta de adaptación social y normativa en relación a las previsiones constitucionales y convencionales.

\section{REFERÉNCIAS}


Rio de Janeiro. Ano 15. Volume 22. Número 3. Setembro a Dezembro de 2021

Periódico Quadrimestral da Pós-Graduação Stricto Sensu em Direito Processual da UERJ

Patrono: José Carlos Barbosa Moreira (in mem.). ISSN 1982-7636. pp. 781-798 www.redp.uerj.br

BERIZONCE R., Los contratos y el negocio jurídico procesal, RDP, Rubinzal-Culzoni ed., Bs.As. 2017-2.

BERIZONCE, R., Revista Derecho y Ciencias Sociales, Abril 2012. No6 (Acceso a la Justicia). Págs. 25-37. ISNN 1852-2971 Instituto de Cultura Jurídica y Maestría en Sociología Jurídica, FCJ y S. UNLP.

CHASE, Oscar. Derecho, cultura y ritual: sistemas de resolución de controversias en un contexto intercultural, Marcial Pons, Ediciones Jurídicas y Sociales, 2011, Madrid. España.

CHAYER, Héctor M.; MARCET Juan Pablo Marcet (dir), Nueva gestión judicial. Oralidad en los procesos civiles, Ciudad Autónoma de Buenos Aires: Ediciones SAIJ, pág.12. Disponible en http://www.saij.gob. ar/docs-f/edic iones/libros/Nuev a_gestion_jud icial.pdf.

FANDIÑO, Marcos (dir.), Estudios Comparados sobre reformas al Sistema de Justicia Civil Australia y Canadá, Volumen II, CEJA, publicado en https://biblioteca.cejamericas.org/handle/2015/5640.

FERRER BELTRÁN, Jordi, 'El Control de La Valoración de La Prueba En Segunda Instancia', Revus, 33, 2017.

MARINONI, L. G., El derecho fundamental de acción, Boletín Mexicano de Derecho Comparado, Nueva Serie, Año XLI, número 123, septiembre diciembre de 2008.

MITIDIERO, Daniel, "Colaboracao no proceso civil", 3era. Edición. Revista dos Tribunais., 2015.

MITIDIERO, Daniel, Precedentes, 3era. ed, San Pablo: Thomson Reuters Brasil, 2018.

MOSMANN, María Victoria, El precedente judicial en Argentina, Revista de Derecho Público 2016-1, Cuestiones Procesales del federalismo argentino, Ed. Rubinzal Culzoni.

MOSMANN, Tutela judicial efectiva, Revista Ius Dictum, Associação Académica da Faculdade de Direito da Universidade de Lisboa, 2020, Phttps://biblioteca.cejam ericas.org/h andle/2015/564 0 Portugal.

Ejecución de Sentencia y Plazo Razonable. Ejecución Anticipada de Sentencia. Revista de Derecho Procesal 2013/2 RubinzalCulzoni. 
Rio de Janeiro. Ano 15. Volume 22. Número 3. Setembro a Dezembro de 2021

Periódico Quadrimestral da Pós-Graduação Stricto Sensu em Direito Processual da UERJ

Patrono: José Carlos Barbosa Moreira (in mem.). ISSN 1982-7636. pp. 781-798 www.redp.uerj.br

OEA/SER.L/V/II.Doc. 6820 enero 2007, “Acceso a la justicia para las mujeres víctima de violencia en las Américas".

OTEIZA - MOSMANN, Tutela Judicial Efectiva: principio y derecho, en proceso de publicación editorial Rubinzal Culzoni.

TARUFFO, Michele, "Poderes probatorios de las partes y del juez en Europa. Doxa. Cuadernos de Filosofía del Derecho", LX(29), 249-271. https://doi.org/10.14198/doxa2006.29.13.

TARUFFO, Michele, Simplemente La Verdad. El Juez y La Construcción de Los Hechos, Madrid: Marcial Pons, 2010.

TARUFFO, Michele, 'Racionalidad y Crisis de La Ley Procesal', Doxa, 22, 1999, 311-20.

UZELAC, Alan (Ed.), Goals of Civil Justice and Civil Procedure in Contemporary Judicial Systems, Ius Gentium:Comparative Perspectives on Law and Justice, 2014.

WORLD JUSTICE PROGRAM (2019) Measuring the justice gap: A People-Centered Assessment of Unmet Justice Needs Around the World. https://worldj usticep roject.org/o ur-work/publications/spe cial-reports /measuring-justice -gap. 